\title{
The history of the emergence and transmission of human coronaviruses
}

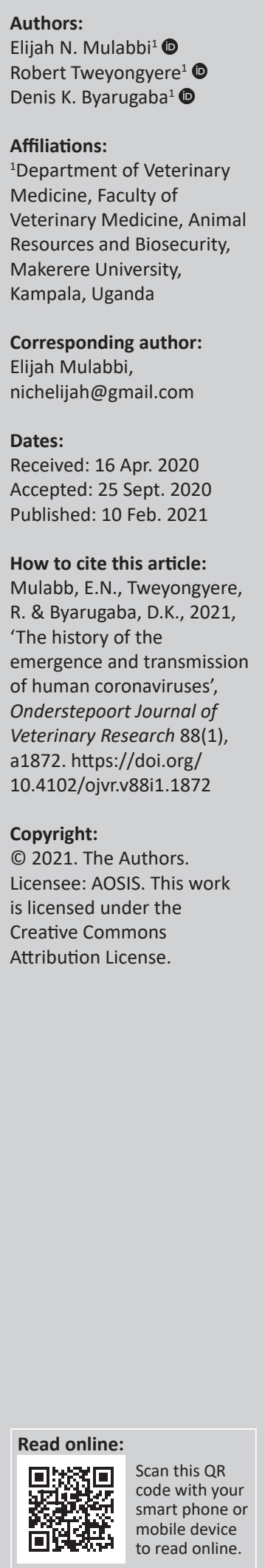

Authors:

$\mathrm{ere}^{1}$

Affiliations:

Department of Veterinary

Veterinary Medicine, Anima

Resources and Biosecurity,

Makerere University,

Corresponding author:

Elijah Mulabbi,

Dates:

Received: 16 Apr. 2020

Accepted: 25 Sept. 2020

How to cite this article:

Mulabb, E.N., Tweyongyere

R. \& Byarugaba, D.K., 2021,

Onderstepoort Journal of

Veterinary Research 88(1)

a1872. https://doi.org/

Copyright:

Licensee: AOSIS. This work

is licensed under the

Creative Commons

mobile device
Human coronaviruses are known respiratory pathogens associated with a range of respiratory illnesses, and there are considerable morbidity and hospitalisation amongst immunecompromised individuals of all age groups. The emergence of a highly pathogenic human coronavirus in China in 2019 has confirmed the long-held opinion that these viruses are important emerging and re-emerging pathogens. In this review article, we trace the discovery and emergence of coronaviruses (CoVs) over time since they were first reported. The review article will enrich our understanding on the host range, diversity and evolution, transmission of human CoVs and the threat posed by these viruses circulating in animal populations but overtime have spilled over to humans because of the increased proximity between humans and animals.

Keywords: Coronaviridae; host range; diversity and evolution; transmission dynamics; mutation; recombination.

\section{Introduction}

Coronaviruses (CoVs) are positive-sense, single-stranded ribonucleic acid (RNA) viruses with a linear, non-segmented viral genome. Amongst all the RNA viruses, they have the largest genome of about $27-32 \mathrm{~kb}$, packed in a helical nucleocapsid. They are named CoVs because of the crownlike appearance of the surface projections. Coronaviruses cause mainly respiratory and enteric diseases in mammals and birds with varying severity (Dijkman et al. 2013; Sipulwa et al. 2016; Weiss \& Navas-Martin 2005). Coronaviruses are the largest group of viruses belonging to order Nidovirales, family Coronaviridae, in the sub-family Coronavirinae. The sub-family Coronavirinae is divided into four genera: the alpha (human coronavirus 229E [HCoV-229E] and human coronavirus NL63 [HCoV-NL63]); beta (human coronavirus OC43 [HCoV-OC43], human coronavirus HKU1 [HCoV-HKU1], severe acute respiratory syndrome coronavirus [SARS-CoV] and Middle East respiratory syndrome-related coronavirus [MERS-CoV]); gamma and deltacoronaviruses (Zhang et al. 2018). The gamma and deltacoronaviruses infect birds. Coronaviruses have a highly conserved genomic organisation with a single large 5 ' open reading frame (ORF), constituting two-thirds of the genome encoding a replicase polyprotein, RNAdependent RNA polymerase (RdRp) (Fehr \& Perlman 2015). This is then followed by several additional ORFs that encode both structural and non-structural proteins. These structural proteins include the nucleocapsid $(\mathrm{N})$ protein, matrix $(\mathrm{M})$ protein, envelope $(\mathrm{E})$ protein and the spike $(\mathrm{S})$ protein (Masters \& Perlman 2013). The spike protein is the major determinant of the virulence of $\mathrm{CoVs}$ because it mediates the binding of the virus to the specific host receptor.

\section{Host range}

Coronaviruses exhibit a broad host range, infecting many mammalian and avian species, where they cause a broad spectrum of diseases in the respective hosts. The specificity to the host is because of the presence of specific receptors in the host, which interact with the CoV through the spike protein during attachment and entry into the host (Lim et al. 2016). It is by this convenience that most CoVs are named based on their host or site in the host at which the pathology manifests. Although this is so, there is a great possibility of cross infection of CoVs because of their ability to jump species barriers, which in result makes them have a broad host range (Cavanagh 2005). Some CoVs are known to be promiscuous being detected in more than one host, like some bovine coronavirus (BCoV, $\mathrm{HCoV}-\mathrm{OC} 43$ and other related viruses), which have been detected in cows, humans, horses, dogs, camels, deer, antelopes and giraffes (Alekseev et al. 2008; Hasoksuz et al. 2007; Jin et al. 2007; Lim et al. 2013), whilst others like the most recently described deltacoronaviruses are host-specific and confined to a single host. Bats have been known to be reservoir hosts of alpha and betacoronaviruses, which predominantly affect mammals, whilst birds are reservoir hosts of gamma and deltacoronaviruses, which affect avian species and some mammalian species (Drexler, 
Corman \& Drosten 2014; Woo et al. 2012). Specifically, the host of HCoV-229E are bats, HCoV-NL63 are bats and palm civets, $\mathrm{HCoV-OC43}$ are cattle, $\mathrm{HCoV}-\mathrm{HKU} 1$ are mice, SARS$\mathrm{CoV}$ are bats and palm Civets, MERS-CoV are bats and camels, and for severe acute respiratory syndrome coronavirus 2 (SARS-CoV-2) the hosts are yet to be established but suspected to be bats and an unknown mammal intermediate host (Bolles, Donaldson \& Baric 2011; Corman et al. 2018; Guo et al. 2020; Reusken et al. 2016). The host receptors of human CoVs have been identified: aminopeptidase $\mathrm{N}$ for $\mathrm{HCoV}$ $229 \mathrm{E}$, angiotensin-converting enzyme 2 for SARS-CoV, SARSCoV-2 and HCoV-NL63, CD26 commonly called dipeptidyl peptidase 4 for MERS-CoV and 9-O-acetylated sialic acid for HCoV-OC43 and HCoV-HKU1 (Bonavia et al. 2003; Hofmann et al. 2005; Huang et al. 2015; Lu, Hu et al. 2013; Van der Hoek 2007; Zou et al. 2020). Having noted earlier that CoVs have the ability to break species barriers, this definitively points to the variations that occur in the spike protein and ultimately the evolution of CoVs.

\section{The sequential discovery of human coronaviruses}

Coronaviruses have been described for close to a century as avian infectious bronchitis virus (IBV), which is the first $\mathrm{CoV}$ to be isolated in 1937, followed by murine hepatitis virus (MHV), which was reported a decade later (Bailey et al. 1949; Cavanagh 2005; Cheever et al. 1949). This shows that animal CoVs have been known since the 1930s, including those that are highly pathogenic to animals, such as transmissible gastroenteritis virus (TGEV), bovine coronavirus (BCoV) and feline infectious peritonitis virus (FIPV) (Saif 2004). The first human $\mathrm{CoV}$ to be isolated was HCoV-229E during a study of respiratory illness amongst medical students in the University of Chicago and was named 229E because it was isolated from student specimen 229E (Hamre \& Procknow 1966). Subsequently, in 1965, viruses B814 and HCoV-OC43 were isolated from patients with common cold. By inoculation onto organ cultures of the respiratory tract, these viruses together with $\mathrm{HCoV}-229 \mathrm{E}$ were shown to have similar morphological characteristics with the IBV of chicken that had been isolated earlier (Hamre \& Procknow 1966; McIntosh et al. 1967; Tyrrell \& Bynoe 1966). Since then, several human and animal CoVs have been studied and have been shown to have a characteristic virion structure by electron microscopy after negative staining. The first diagnostic assays were based on tissue cultures and serological surveillance by measuring the significant rise in antibody titer. $\mathrm{HCoV}-229 \mathrm{E}$ and $\mathrm{HCoV}$ OC43 were the only strains followed up after 1965 up to 1990s because they were the only strains that could easily be cultured, the other strains (OC16, OC37, OC38, OC44 and OC48) including the first identified human $\mathrm{CoV}$, B814, were lost because of the inability to culture then; thus, no further investigations could be done on them (Van der Hoek 2007). With increasing research and discovery of new scientific techniques, the number and the importance of CoVs have grown exponentially; there has been discovery of many novel CoVs in animals and humans. Before 2002, only HCoV
229E and $\mathrm{HCoV}$ OC43 were known to be circulating in human population causing common cold, and they were relatively considered as harmless because they caused mild illness. However, in 2002, a CoV causing severe acute respiratory illness was discovered and was named severe acute respiratory syndrome coronavirus (SARS-CoV). Severe acute respiratory syndrome coronavirus initially emerged in 2002-2003 in Guangdong province in South China and caused severe respiratory infection with high morbidity and mortality that had not been experienced with $\mathrm{CoVs}$ before. The disease was more pronounced in the elderly, infants and those with underlying conditions that make them immunocompromised (Tsang \& Zhong 2003). Although SARS-CoV disappeared a year after its emergence (Feng \& Gao 2007), new strains of CoVs have continuously been discovered, and indeed in 2003, two more CoVs were discovered - HCoV-NL63 and HCoV-HKU1 (Drexler et al. 2014; Van der Hoek et al. 2004; Woo et al. 2005). HCoV-NL63 was isolated in the Netherlands in 2003 from a child suffering from bronchiolitis and conjunctivitis, and this was not an isolated case as the virus was identified in clinical specimens from seven additional individuals who included infants and adults (Van der Hoek et al. 2004). In 2004, HKU1 was discovered in Hong Kong from a 71-year-old man with pneumonia who had just returned from Shenzhen, China (Woo et al. 2005). Ten years after the discovery of SARS-CoV, another human $\mathrm{CoV}$ that causes severe respiratory illness was discovered in 2012, initially named Human Coronavirus Erasmus Medical Center (HCoV-EMC), but later the international committee on the taxonomy of viruses named it Middle East Respiratory Syndrome (MERS) CoV (Chan et al. 2015; De Groot et al. 2013; Zaki et al. 2012). MERS-CoV was first identified in Saudi Arabia from a 60-year-old man with acute pneumonia, developed respiratory distress, renal failure and finally succumbed to the disease (Widagdo et al. 2017). MERS-CoV causes a series of highly pathogenic lower respiratory tract infections with a higher case fatality rate of $35 \%$ compared to $11 \%$ of SARS-CoV (Chan-Yeung \& Xu 2003; Donnelly et al. 2019). However, unlike SARS which disappeared a year after its discovery, MERS has remained causing outbreaks in the Middle East, notably in Saudi Arabia (2014-2016) and in South Korea (2015) (Berry, Gamieldien \& Fielding 2015; Fehr \& Perlman 2015). Just 7 years after the discovery of MERS-CoV, in December 2019, a novel human $\mathrm{CoV}$ that is similar to SARS-CoV was discovered and isolated from patients in the Hubei Province, China, suffering from pneumonia, but has since spread to many countries across all continents (Zhu et al. 2020). This novel virus causes coronavirus disease (COVID-19), which has been declared a pandemic by the World Health Organisation (Summers et al. 2020). This novel CoV, initially designated as 2019-nCoV but now named SARS-CoV-2, forms the seventh CoV that infects humans (Zhu et al. 2020).

\section{Diversity and evolution of coronaviruses}

In all the CoVs that have so far been reported, occurrence has been spontaneous and their source has been mysterious. Schools of thought have suggested recombination and the 
low fidelity of the RdRp as the main contributing factors that drive the evolution and diversity of the different CoVs with their hosts.

Recombination involves the exchange of genetic information between two non-segmented RNA genomes, contributing to the genetic stability of picoraviruses and CoVs where it has been demonstrated to occur (Lai et al. 1985). Homologous recombination occurs between two regions of high sequence similarity of a single strain of a CoV. Ribonucleic acid recombination in $\mathrm{CoVs}$ can occur almost anywhere on the genome, forming many recombinants with multiple crossover events. This shows that CoVs have a high frequency of recombination, which gives them an emergence and epidemiological advantage (Lai 1992a). The frequency of recombination in $\mathrm{CoVs}$ is so high that even in the absence of selection pressure, recombinants can be formed and can become the most dominant population amongst the viruses (Lai 1992b; Simon-Loriere \& Holmes 2011). Non-homologous recombination occurs if a cell is infected by two strains of a given species of $\mathrm{CoV}$, and exchange between genetically different RNA genomes can occur resulting in a progeny with the sequence derived from both the parent strains (Cavanagh 2005; Simon-Loriere \& Holmes 2011). Although the probability of this non-homologous recombination amongst distantly related strains is small because of the need of sequence similarity, it is quite common in CoVs.

Coronaviruses have a mutation frequency just like other RNA viruses because of the error-prone RdRp, which lacks a proofreading and mismatch repair capability. Mismatch repair processes are not possible for genomes of most RNA viruses because they replicate and package single-stranded genomes. The only mechanism of correcting the mismatch would be a replicase-associated proofreading mechanism that the polymerase lacks (Elena \& Sanjuán 2005; Steinhauer, Domingo \& Holland 1992). This makes CoVs have high mutation rates, which can result in potentially adaptively useful genetic variation (Drake et al. 1998). All these events, together with re-assorting mutations, give CoVs a potential to generate novel viral phenotypes by expanding their repertoire of essential genes with many new genes (Forni et al. 2017). This plasticity of the genome provides CoVs a selective advantage and fast adaptability to usual and unusual natural hosts propelling them along the evolution path and may yield virus strains of unexpected virulence.

All human CoVs originate from bats; so, bats definitely play an important role as the gene source in the evolution of human CoVs. In the lineage of bat CoVs, they are known to have jumped to other bat species and other mammalian species including humans, with each interspecies jumping resulting in dichotomous evolution to give rise to alphacoronaviruses and betacoronaviruses (Woo et al. 2012). This jumping phenomenon is quite common in the lineage of CoVs although the mechanism by which they jump and switch to new hosts is not clearly understood. The great diversity of CoVs circulating in the bats has been attributed to their rich species diversity, high population densities and the ability to fly over long distances. The frequency and diversity of CoVs in bats have been globally detected in all continents with appreciable genetic similarity to human CoVs (Anthony et al. 2017; Li et al. 2005; Tong et al. 2009).

\section{Inter-host transmission of coronaviruses: What is known}

As noted earlier that bats and birds are reservoir hosts of all the $\mathrm{CoVs}$ and act as the gene source in the evolution pathway of these viruses, transmission starts from them although the mechanism of zoonotic transmission from bats to humans is unclear. It has, however, been suggested that intermediate hosts such as carnivores or herbivores are involved in the transmission of these viruses (Cotten et al. 2013; Enserink 2013; Graham \& Baric 2010).

Human coronavirus 229E (HCoV-229E) and Alpaca-CoV have been shown to have a close relationship with the diverse CoVs that exist in hipposiderid bats in Africa, which are the natural hosts of that lineage (Corman et al. 2015). Humans can come into contact with hipposiderid bats in their natural habitats, which can suggest direct transmission of $\mathrm{HCoV}$ 229E from bats rather than from alpaca, which do not share habitats with these bats. However, further analysis shows that $\mathrm{CoVs}$ that have close genomic similarity with $\mathrm{HCoV}$ $229 \mathrm{E}$ occur in camelids and suggests that $\mathrm{HCoV}-229 \mathrm{E}$ evolved towards the human genotype in camelids thereby identifying camelids as the zoonotic source of human infection. The host switching of $229 \mathrm{E}$ virus from bats to humans must have been facilitated by deletions in the spike gene of the bat-associated 229E viruses (Corman et al. 2018).

Human coronavirus OC43 (HCoV-OC43) is a betacoronavirus. Betacoronaviruses have strains circulating in many highly divergent mammalian hosts such as primates, lagomorphs, artiodactyls, perissodactyls, rodents and carnivores (Alekseev et al. 2008; Drexler et al. 2014; Erles et al. 2003; Guy et al. 2000; Hasoksuz et al. 2007; Lau et al. 2012; Lim et al. 2013; Majhdi, Minocha \& Kapil 1997; Tsunemitsu et al. 1995; Woo et al. 2014). Bovine coronavirus is the best studied representative of these animal CoVs; the great diversity of Beta-CoVs in livestock suggests them to be the zoonotic sources of HCoV-OC43. Like other CoVs, mutations in the spike gene reflect the adaptation of $\mathrm{HCoV}-\mathrm{OC} 43$ to the human host. HCoV-OC43, like other Beta-CoVs, have no ancestral link to bats but rather to rodents because of their close similarity to mouse hepatitis virus (MHV), thus believed to have speciated in rodents (Corman et al. 2018). The mechanism of transmission from rodents to bovine is not well documented but the close proximity between humans and bovine causes the spillover to humans.

Human coronavirus NL63 (HCoV-NL63) has been found to be related to $\mathrm{CoVs}$ of bats in the families Vespertillionidae and Hipposideridae, which points to the ancestry origin of $\mathrm{HCoV}$ - 
NL43 (Drexler et al. 2010; Gloza-Rausch et al. 2008; Pfefferle et al. 2009; Tao et al. 2017). The mechanism of transmission of HCoV-NL43 to humans is not documented with no zoonotic reservoir so far identified.

There is no viral sequences relating $\mathrm{HCoV}-\mathrm{HKU} 1$ to other animal species, save the relationship it has with rodentassociated viruses (Wang et al. 2015; Woo et al. 2005). Just like HCoV-NL63, the mechanism of transmission of HCoV-HKU1 to humans is not documented with no zoonotic reservoir so far identified.

Considering the recent epidemics in humans with the spread of SARS-CoV, MERS-CoV and SARS-CoV-2, new insights have occurred in the transmission patterns of CoVs.

SARS-CoV was previously thought to have originated from wild animals, the civet cats, raccoon, dogs and ferret-badger (Guan et al. 2003) but cumulative phylogenetic studies have pointed to a bat origin of SARS-CoV. This is because there is no evidence for the circulation of SARS-CoV like viruses in palm civets in both the wild and breeding facilities (Wang et al. 2006). Therefore, these animals are only incidental hosts of SARS-CoV, and the live markets were probably sites where the interspecies transfer of the animal virus to human occurred (Weiss \& Navas-Martin 2005). SARS-CoV has been reported to infect macaque monkeys and domestic cats but transmission from these domestic cats to man has not been demonstrated (Fouchier et al. 2003; Navas-Martin \& Weiss 2003). However, its ability to infect other animals suggests that SARS-CoV could be having a natural wild reservoir from which future outbreaks can originate.

The first search for the reservoir of MERS-CoV focused on bats because of the genetic close relatedness of MERS-CoV to Tylonycteris bat CoV HKU4 and Pipistrellus bat CoV KHU5. However, molecular clock analysis suggested that these bat CoVs are unlikely to be the direct ancestor of MERS-CoV (Chan, Lau \& Woo 2013). Molecular and serological surveys in dromedary camels from Oman, Canary Islands, Qatar and Saudi Arabia give evidence that these animals are the reservoir of MERS-CoV (Azhar et al. 2014; Haagmans et al. 2014; Raj et al. 2014; Reusken et al. 2013). Dromedary camels in Saudi Arabia harbour several viral genetic lineages including those that actually caused human outbreaks, and in addition, an infectious virus has been isolated from them pointing at their important role in the transmission of MERS-CoV (Sabir et al. 2016). The closeness of dromedary camels to humans results in continuous zoonotic transmission of the MERS-CoV to humans, thus explaining the cause of new infection in humans compared to SARS-CoV, where no new infections have been reported in humans since January 2004 because there is limited human-bat or human-intermediate host interactions (Baseler et al. 2016; Wang, Potter et al. 2005).

Severe acute respiratory syndrome coronavirus 2 (SARS$\mathrm{CoV}-2)$, the newly discovered human $\mathrm{CoV}$, has been linked to a zoonotic source with a spillover to humans at Huanan Seafood Wholesale Market in Wuhan, China. There were a number of non-aquatic birds and rabbits that were on sale in that market before the outbreak (Mackenzie \& Smith 2020). Through next-generation sequencing, SARS-CoV has been showed to be closely related to two bat-derived SARS-like CoVs, bat-SLCoVZC45 and bat-SLCoVZXC21, which have been previously characterised from bats in China (Hu et al. 2018). This is consistent with the fact that bats are natural reservoirs of CoVs. Just like other human CoVs that have intermediate hosts, it is likely that SARS-CoV-2 has an unidentified intermediate animal host sold in the seafood market from which the virus spread to humans (Li, Zai et al. 2020; Liu et al. 2020). This is so because there is no proof that there was proximity between humans and bats that host the virus, because in December the bats are known to have been hibernating (Lu et al. 2020). The genomic sequences of SARSCoV 2 from different patients have a 99.9\% identity, which suggested that the virus originated from one source within a very short period and spread quite rapidly.

\section{Human-to-human transmission of coronaviruses}

Once zoonotic viruses have succeeded in breaking the species barrier to infect humans, their success in the human population depends on its ability to acquire sustained human-to-human transmissibility. Human-to-human transmission of CoVs occurs directly or indirectly through airborne route or contact route. Direct transmission requires the physical contact between an infected person and a healthy person, followed by the transfer of the virus through touching, contact with body fluids and inhalation of respiratory secretions. Indirect transmission requires contact between a susceptible person with a contaminated surface and resultant transfer of the virus into entry points into the body like the respiratory pathway.

The four human CoVs that are endemic in human populations and cause self-limiting common cold (HCoV 229E, HKU1, NL63 and OC43) are droplet-transmitted; these viruscontaining droplets are released to the environment when an infected person breathes, coughs, sneezes or talks. This efficient human-to-human transmission of these virus is sustainable because these viruses replicate mainly in the central and upper parts of the respiratory tract (Perlman \& Netland 2009; Richard et al. 2017; Wege \& Ter Meulen 1982). Sustainable human-to-human transmission is also dependent on the stability of the viruses in the environment. Large virus-containing droplets released from infected persons do not remain suspended in the air for long but rather move for a short distance and surfaces or mucosa of close contacts. Smaller droplets can remain suspended in air for long period of time and carried further from the infected person. $\mathrm{HCoV}$ NL63 can survive for 7 days in aqueous solution and respiratory sections and remains infective at room temperature for long (Abdul-Rasool \& Fielding 2010; Müller et al. 2008). HCoV-229E can survive and be detectable after 6 days at $20{ }^{\circ} \mathrm{C}$ and $50 \%$ relative humidity; this survival can 
be enhanced further at lower temperature and higher humidity (Ijaz et al. 1985). Literature about the stability in the environment of HCoV-KU1 and $\mathrm{HCoV}-\mathrm{OC} 43$ is scanty but human-to-human transmission is the documented mode of transmission.

Human-to-human transmission of SARS-CoV and MERS$\mathrm{CoV}$ occurs through modes like droplets, direct human-to-human transmission and through fomites. However, long-term and sustained human-to-human transmission has not been established in these zoonotic viruses. MERS-CoV has a lower human-to-human transmission than that of SARS-CoV (Lu, Liu et al. 2013). Human-to-human transmission of SARS-CoV occurs rapidly, which explained the rapid spread of SARS across 29 countries within only 6 months (Groneberg et al. 2003; Peiris, Yuen et al. 2003). Three instances of laboratory-acquired SARS$\mathrm{CoV}$ infection were reported in Singapore, China and Taiwan, but in each of these cases, there were no sustained human-tohuman transmission to cause a threat of a recurrent global outbreak but rather highlighted the potential risk when biosafety procedures in the laboratory are not adhered to (Enserink \& Du 2004; Liang et al. 2004; Lim et al. 2004). Human-to-human transmissions amongst family members contributed only $13 \%-21 \%$ of the MERS cases and $22 \%-$ $39 \%$ SARS cases. This shows that the nosocomial route is the main route of transmission of these viruses because substantial virus shedding occurs only after the onset of symptoms and that is when patients seek treatment in medical centres (Anderson et al. 2004; Baseler et al. 2016; Cowling et al. 2015; Peiris, Lai et al. 2003). Studies showed that $44 \%-100 \%$ of the MERS-CoV-infected individuals during the outbreak were linked to hospitals where they got the infection, and a similar observation was made for some clusters of SARS patients (Chowell et al. 2015; Hunter et al. 2016). MERS-CoV remains stable and viable for $48 \mathrm{~h}$ at $20^{\circ} \mathrm{C}$ and $40 \%$ relative humidity, whilst SARS-CoV for 5 days at $22{ }^{\circ} \mathrm{C}-25{ }^{\circ} \mathrm{C}$ and $40 \%-50 \%$ relative humidity. However, both lose viability rapidly at a higher temperature and humidity (Van Doremalen, Bushmaker \& Munster 2013). This stability enables these viruses to be transmitted as aerosols; because SARS-CoV is more stable, it has a more sustained transmission than MERS-CoV through aerosols. Fomite transmission of these viruses is possible because of the stability of these viruses; they stay on inanimate surfaces long enough such that by the time humans touch the surfaces, they get infected (Lee \& Wong 2015). This explains the infection of humans who were not in close proximity with index patients in the respective outbreaks. SARS-CoV was shown to be excreted in stool and remains infectious in sewerage for 2 days; therefore, broken sewerage systems can be a mechanism of spread of SARS-CoV (Wang, Li et al. 2005).

The newly identified SARS-CoV-2 has been suggested to be transmitted through droplet transmission and human-to-human transmission as evidenced with clusters of infected families and medical workers who have not had any exposure to animal markets where the infection started (Carlos et al. 2020; Chang et al. 2020; Li, Guan et al. 2020; Wang et al. 2020). Just like other $\mathrm{HCoVs}$, nosocomial transmission has been implicated as an important mode of acquiring infection; actually one study suggested hospital transmission to be $41 \%$ amongst the patients (Wang et al. 2020). The stability of SARS-CoV-2 on contaminated surfaces and remaining viable for hours in aerosols or days on surfaces allow virus transmission through aerosols and fomites (Van Doremalen et al. 2020). SARS-CoV-2 has been detected in stool, suggesting that viral shading in stool is a potential route of transmission when persons get in contact with contaminated sewerage and also points to the possibility of fecal-oral transmission of the virus (Young et al. 2020). In comparison with SARS-CoV and MERS-CoV, where intestinal infections were observed at some later stages of infection, patients infected with SARS-CoV-2 may harbour the virus in the intestine in the early or later stages of infection. Detection of SARS-CoV in oral swabs, anal swabs and blood point to body fluids as an alternative mode of transmission through body fluids (Zhang et al. 2020). There are more studies being done, which will improve our understanding on the human-to-human transmission dynamics of SARS-CoV-2.

\section{Conclusion}

Human $\mathrm{CoV}$ s are increasingly becoming important emerging pathogens from the previously known mild infections to severe acute respiratory infection with high fatality rates. Like other emerging pathogens, human CoVs pose a challenge to science and medicine because of the scantly information about them before they emerge from initially unknown zoonotic sources. With the increasing human population and climate change, people have increased proximity with animals, be either encroaching on their habitats or trade, and therefore zoonotic spillover of these viruses is continuously likely to occur. The biggest challenge here is that therapies and vaccination remedies have not been developed to match the emergence of these viruses, leaving treatment to be limited to non-specific supportive therapy. Since bats have been known to be an important reservoir of human viruses for several years, there should be continuous efforts to characterise the CoVs circulating in bat populations. There is a need to study the mechanisms through which these viruses find their way to the intermediate hosts because these intermediate hosts play an important role in linking bats to human populations. The possibility of direct transmission from bats to humans can also be investigated. Not only should these intermediate hosts be identified but also viral surveillance studies have to be expanded to wild and domestic animals such as bovine, rodents and carnivores in order to establish the important human CoVs that occur in these animals before they spill over to humans and cause pandemics. Mutations and recombination that occur in RNA viruses should be the contributory factor in the emergence of these viruses where they become able to utilise the human receptors that are required for successful infection and the progress of disease. Therefore, there is continuous need to monitor the effect of these mutations that occur in these viruses over a given period of time such that their emergence does not take the 
population by surprise and also precautionary measures should be taken early enough. With lack of therapies, avenues of animal-to-human transmissions must be blocked. This will require stringent regulatory mechanisms to control the trading of wild species in markets, creating buffer zones around habitats of wild animals and also an overall change in the cultural practices of communities. These can be enriched with the other avenues that are popularly used such as case isolation, quarantine and limiting the overall population mobility in this era where there is rapid expansion of transport networks. The One Health concept will always be a great approach in detecting, containing and eliminating public health risks from zoonotic pathogens.

\section{Acknowledgements}

The authors wish to acknowledge the Makerere Univeristy Walter Reed Project and the staff of the Emerging Infectious Diseases Laboratory.

\section{Competing interests}

The authors declare that they have no financial or personal relationships that may have inappropriately influenced them in writing this article.

\section{Authors' contributions}

M.N.E. is the corresponding author, wrote the draft of the review article and R.T. and D.K.B. read and gave comments for improving the manuscript.

\section{Ethical consideration}

The authors confirm that ethical clearance was not required for the study.

\section{Funding information}

This review article received no specific grant from any funding agency in the public, commercial or not-for-profit sectors.

\section{Data availability statement}

Data sharing is not applicable to this article as no new data were created whilst writing this review article.

\section{Disclaimer}

The views and opinions expressed in this article are those of the authors and do not necessarily reflect the official policy or position of any affiliated agency of the authors.

\section{References}

Abdul-Rasool, S. \& Fielding, B.C., 2010, 'Understanding human coronavirus HCoV-NL63', The Open Virology Journal 4, 76. PMID: 20700397.

Alekseev, K.P., Vlasova, A.N., Jung, K., Hasoksuz, M., Zhang, X., Halpin, R. et al., 2008 , 'Bovine-like coronaviruses isolated from four species of captive wild ruminants are homologous to bovine coronaviruses, based on complete genomic sequences', Journal of Virology 82(24), 12422-12431. https://doi.org/10.1128/JVI.01586-08
Anderson, R.M., Fraser, C., Ghani, A.C., Donnelly, C.A., Riley, S., Ferguson, N.M. et al., 2004, 'Epidemiology, transmission dynamics and control of SARS: The 2002-2003 epidemic', Philosophical Transactions of the Royal Society B: Biological Sciences 359(1447), 1091-1105. https://doi.org/10.1098/rstb.2004.1490

Anthony, S.J., Gilardi, K., Menachery, V., Goldstein, T., Ssebide, B., Mbabazi, R. et al., 2017, 'Further evidence for bats as the evolutionary source of Middle East respiratory syndrome coronavirus', MBio 8(2), e00373-00317. https://doi. org/10.1128/mBio.00373-17

Azhar, E.I., El-Kafrawy, S.A., Farraj, S.A., Hassan, A.M., Al-Saeed, M.S., Hashem, A.M et al., 2014, 'Evidence for camel-to-human transmission of MERS coronavirus', New England Journal of Medicine 370(26), 2499-2505. https://doi.org/10.1056/ NEJMoa1401505

Bailey, O.T., Pappenheimer, A.M., Cheever, F.S. \& Daniels, J.B., 1949, 'A murine virus (JHM) causing disseminated encephalomyelitis with extensive destruction of myelin: II. Pathology', Journal of Experimental Medicine 90(3), 195-212. https:// doi.org/10.1084/jem.90.3.195

Baseler, L.J., Falzarano, D., Scott, D.P., Rosenke, R., Thomas, T., Munster, V.J. et al., 2016, 'An acute immune response to Middle East respiratory syndrome coronavirus replication contributes to viral pathogenicity', The American Journa of Pathology 186(3), 630-638. https://doi.org/10.1016/j.ajpath.2015.10.025

Berry, M., Gamieldien, J. \& Fielding, B.C., 2015, 'Identification of new respiratory viruses in the new millennium', Viruses 7(3), 996-1019. https://doi.org/10.3390/ v7030996

Bolles, M., Donaldson, E. \& Baric, R., 2011, 'SARS-CoV and emergent coronaviruses: Viral determinants of interspecies transmission', Current Opinion in Virology 1(6), 624-634. https://doi.org/10.1016/j.coviro.2011.10.012

Bonavia, A., Zelus, B.D., Wentworth, D.E., Talbot, P.J. \& Holmes, K.V., 2003, Identification of a receptor-binding domain of the spike glycoprotein of human coronavirus HCoV-229E', Journal of Virology 77(4), 2530-2538. https://doi. org/10.1128/JVI.77.4.2530-2538.2003

Carlos, W.G., Dela Cruz, C.S., Cao, B., Pasnick, S. \& Jamil, S., 2020, 'Novel Wuhan (2019nCoV) coronavirus', American Journal of Respiratory and Critical Care Medicine 201(4), P7-P8. https://doi.org/10.1164/rccm.2014P7

Cavanagh, D., 2005, 'Coronaviridae: A review of coronaviruses and toroviruses', in A. Schmidt, O. Weber, M.H. Wolff (eds), Coronaviruses with special emphasis on first insights concerning SARS, pp. 1-54, Birkhäuser Advances in Infectious Diseases BAID, Birkhäuser Basel, Springer. https://doi.org/10.1007/3-7643-7339-3_1

Chan, J.F., Lau, S.K., To, K.K., Cheng, V.C., Woo, P.C. \& Yuen, K.-Y., 2015, 'Middle East respiratory syndrome coronavirus: Another zoonotic betacoronavirus causing respiratory syndrome coronavirus: Another zoonotic betacoronavirus causing
SARS-like disease', Clinical Microbiology Reviews 28(2), 465-522. https://doi. org/10.1128/CMR.00102-14

Chan, J.F.-W., Lau, S.K.-P. \& Woo, P.C.-Y., 2013, 'The emerging novel Middle East respiratory syndrome coronavirus: The "knowns" and "unknowns"', Journal of the Formosan Medical Association 112(7), 372-381. https://doi.org/10.1016/j. jfma.2013.05.010

Chang, D., Lin, M., Wei, L., Xie, L., Zhu, G., Cruz, C.S.D. et al., 2020, 'Epidemiologic and clinical characteristics of novel coronavirus infections involving 13 patients outside Wuhan, China', Jama 323(11), 1092-1093. https://doi.org/10.1001/jama.2020.1623

Chan-Yeung, M. \& Xu, R.H., 2003, 'SARS: Epidemiology', Respirology 8(1) , S9-S14. https://doi.org/10.1046/j.1440-1843.2003.00518.x

Cheever, F.S., Daniels, J.B., Pappenheimer, A.M. \& Bailey, O.T., 1949, 'A murine virus $(\mathrm{JHM})$ causing disseminated encephalomyelitis with extensive destruction of myelin: I. Isolation and biological properties of the virus', The Journal of Experimental Medicine 90(3), 181. https://doi.org/10.1084/jem.90.3.181

Chowell, G., Abdirizak, F., Lee, S., Lee, J., Jung, E., Nishiura, H. et al., 2015, 'Transmission characteristics of MERS and SARS in the healthcare setting: A comparative study', BMC Medicine 13(1), 210. https://doi.org/10.1186/s12916-015-0450-0

Corman, V.M., Baldwin, H.J., Tateno, A.F., Zerbinati, R.M., Annan, A., Owusu, M. et al., 2015 , 'Evidence for an ancestral association of human coronavirus $229 \mathrm{E}$ with bats', Journal of Virology 89(23), 11858-11870. https://doi.org/10.1128/ JVI.01755-15

Corman, V.M., Muth, D., Niemeyer, D. \& Drosten, C., 2018, 'Hosts and sources of endemic human coronaviruses', in M. Kielian, C.T. Mettenleiter \& M.J. Roossinck (eds.), Advances in virus research, vol. 100, pp. 163-188, Academic Press. https:// doi.org/10.1016/bs.aivir.2018.01.001.

Cotten, M., Watson, S.J., Kellam, P., Al-Rabeeah, A.A., Makhdoom, H.Q., Assiri, A. et al., 2013, 'Transmission and evolution of the Middle East respiratory syndrome coronavirus in Saudi Arabia: A descriptive genomic study', The Lancet 382(9909), 1993-2002. https://doi.org/10.1016/S0140-6736(13)61887-5

Cowling, B.J., Park, M., Fang, V.J., Wu, P., Leung, G.M. \& Wu, J.T., 2015, 'Preliminary epidemiologic assessment of MERS-CoV outbreak in South Korea, May-June 2015', Euro Surveillance: Bulletin Europeen sur les maladies transmissibles= European communicable disease bulletin 20(25), 7-13. https://doi. org/10.2807/1560-7917.ES2015.20.25.21163

De Groot, R.J., Baker, S.C., Baric, R.S., Brown, C.S., Drosten, C., Enjuanes, L. et al., 2013 , 'Middle East respiratory syndrome coronavirus (MERS-CoV): Announcement of the coronavirus study group', Journal of Virology 87(14), 7790-7792. https://doi. org/10.1128/JVI.01244-13

Dijkman, R., Jebbink, M.F., Koekkoek, S.M., Deijs, M., Jónsdóttir, H.R., Molenkamp, R. et al., 2013, 'Isolation and characterization of current human coronavirus strains in primary human epithelial cell cultures reveal differences in target cell tropism' Journal of Virology 87(11), 6081-6090. https://doi.org/10.1128/JVI.03368-12

Donnelly, C.A., Malik, M.R., Elkholy, A., Cauchemez, S. \& Van Kerkhove, M.D., 2019, 'Worldwide reduction in MERS cases and deaths since 2016', Emerging Infectious Diseases 25(9), 1758. https://doi.org/10.3201/eid2509.190143 
Drake, J.W., Charlesworth, B., Charlesworth, D. \& Crow, J.F., 1998, 'Rates of spontaneous mutation', Genetics 148(4), 1667-1686.

Drexler, J.F., Corman, V.M. \& Drosten, C., 2014, 'Ecology, evolution and classification of bat coronaviruses in the aftermath of SARS', Antiviral Research 101, 45-56. https://doi.org/10.1016/j.antiviral.2013.10.013

Drexler, J.F., Gloza-Rausch, F., Glende, J., Corman, V.M., Muth, D., Goettsche, M. et al., 2010, 'Genomic characterization of severe acute respiratory syndrome-related coronavirus in European bats and classification of coronaviruses based on partia RNA-dependent RNA polymerase gene sequences', Journal of Virology 84(21), 11336-11349. https://doi.org/10.1128/JVI.00650-10

Elena, S.F. \& Sanjuán, R., 2005, 'Adaptive value of high mutation rates of RNA viruses: Separating causes from consequences', Journal of Virology 79(18), 11555-11558. https://doi.org/10.1128/JVI.79.18.11555-11558.2005

Enserink, M., 2013, Amid heightened concerns, new name for novel coronavirus emerges, Science 340(6133), 673. https://doi.org/10.1126/science.340.6133.673

Enserink, M. \& Du, L., 2004, 'China dumps CDC head, probes lab', Science 305(5681), 163. https://doi.org/10.1126/science.305.5681.163a

Erles, K., Toomey, C., Brooks, H.W. \& Brownlie, J., 2003, 'Detection of a group 2 coronavirus in dogs with canine infectious respiratory disease', Virology 310(2), 216-223. https://doi.org/10.1016/S0042-6822(03)00160-0

Fehr, A.R. \& Perlman, S., 2015, 'Coronaviruses: An overview of their replication and pathogenesis', Methods in Molecular Biology, Vol. 1282, pp. 1-23, Humana Press, New York, NY. https://doi.org/10.1007/978-1-4939-2438-7_1

Feng, Y. \& Gao, G.F., 2007, 'Towards our understanding of SARS-CoV, an emerging and devastating but quickly conquered virus', Comparative Immunology, Microbiology and Infectious Diseases 30(5-6), 309-327. https://doi.org/10.1016/j. cimid.2007.05.009

Forni, D., Cagliani, R., Clerici, M. \& Sironi, M., 2017, 'Molecular evolution of human coronavirus genomes', Trends in Microbiology 25(1), 35-48. https://doi. org/10.1016/j.tim.2016.09.001

Fouchier, R.A., Kuiken, T., Schutten, M., Van Amerongen, G., Van Doornum, G.J., Van den Hoogen, B.G. et al., 2003, 'Aetiology: Koch's postulates fulfilled for SARS virus', Nature 423(6937), 240. https://doi.org/10.1038/423240a

Gloza-Rausch, F., Ipsen, A., Seebens, A., Göttsche, M., Panning, M., Drexler, J.F. et al. 2008, 'Detection and prevalence patterns of group I coronaviruses in bats, Northern Germany', Emerging Infectious Diseases 14(4), 626. https://doi. org/10.3201/eid1404.071439

Graham, R.L. \& Baric, R.S., 2010, 'Recombination, reservoirs, and the modular spike: Mechanisms of coronavirus cross-species transmission', Journal of Virology 84(7), 3134-3146. https://doi.org/10.1128/JVI.01394-09

Groneberg, D., Zhang, L., Welte, T., Zabel, P. \& Chung, K., 2003, 'Severe acute respiratory syndrome: Global initiatives for disease diagnosis', QJM 96(11), 845-852. https://doi.org/10.1093/qjmed/hcg146

Guan, Y., Zheng, B., He, Y., Liu, X., Zhuang, Z., Cheung, C. et al., 2003, 'Isolation and characterization of viruses related to the SARS coronavirus from animals in Southern China', Science 302(5643), 276-278. https://doi.org/10.1126/ science.1087139

Guo, Y.-R., Cao, Q.-D., Hong, Z.-S., Tan, Y.-Y., Chen, S.-D., Jin, H.-J. et al., 2020, 'The origin, transmission and clinical therapies on coronavirus disease 2019 (COVID-19) outbreak-an update on the status', Military Medical Research 7(1), 1-10. https:// doi.org/10.1186/s40779-020-00240-0

Guy, J.S., Breslin, J.J., Breuhaus, B., Vivrette, S. \& Smith, L.G., 2000, 'Characterization of a coronavirus isolated from a diarrheic foal', Journal of Clinical Microbiology 38(12), 4523-4526. https://doi.org/10.1128/JCM.38.12.4523-4526.2000

Haagmans, B.L., Al Dhahiry, S.H., Reusken, C.B., Raj, V.S., Galiano, M., Myers, R. et al., 2014, 'Middle East respiratory syndrome coronavirus in dromedary camels: An outbreak investigation', The Lancet Infectious Diseases 14(2), 140-145. https:// doi.org/10.1016/S1473-3099(13)70690-X

Hamre, D. \& Procknow, J.J., 1966, 'A new virus isolated from the human respiratory tract', Proceedings of the Society for Experimental Biology and Medicine 121(1) 190-193. https://doi.org/10.3181/00379727-121-30734

Hasoksuz, M., Alekseev, K., Vlasova, A., Zhang, X., Spiro, D., Halpin, R. et al., 2007, 'Biologic, antigenic, and full-length genomic characterization of a bovine-like coronavirus isolated from a giraffe', Journal of Virology 81(10), 4981-4990. https://doi.org/10.1128/JVI.02361-06

Hofmann, H., Pyrc, K., van der Hoek, L., Geier, M., Berkhout, B. \& Pöhlmann, S., 2005 'Human coronavirus NL63 employs the severe acute respiratory syndrome coronavirus receptor for cellular entry', Proceedings of the National Academy of Sciences 102(22), 7988-7993. https://doi.org/10.1073/pnas.0409465102

Hu, D., Zhu, C., Ai, L., He, T., Wang, Y., Ye, F. et al., 2018, 'Genomic characterization and infectivity of a novel SARS-like coronavirus in Chinese bats', Emerging Microbes \& Infections 7(1), 1-10. https://doi.org/10.1038/s41426-018-0155-5

Huang, X., Dong, W., Milewska, A., Golda, A., Qi, Y., Zhu, Q.K. et al., 2015, 'Human coronavirus HKU1 spike protein uses O-acetylated sialic acid as an attachment receptor determinant and employs hemagglutinin-esterase protein as a receptordestroying enzyme', Journal of Virology 89(14), 7202-7213. https://doi. org/10.1128/JVI.00854-15

Hunter, J.C., Nguyen, D., Aden, B., Al Bandar, Z., Al Dhaheri, W., Elkheir, K.A. et al., 2016, 'Transmission of Middle East respiratory syndrome coronavirus infections in healthcare settings, Abu Dhabi', Emerging Infectious Diseases 22(4), 647. https:// doi.org/10.3201/eid2204.151615 ljaz, M., Brunner, A., Sattar, S., Nair, R.C. \& Johnson-Lussenburg, C., 1985, 'Survival characteristics of airborne human coronavirus 229E', Journal of General Virology 66(12), 2743-2748. https://doi.org/10.1099/0022-1317-66-12-2743

Jin, L., Cebra, C., Baker, R., Mattson, D., Cohen, S., Alvarado, D. et al., 2007, 'Analysis of the genome sequence of an alpaca coronavirus', Virology 365(1), 198-203. https://doi.org/10.1016/j.virol.2007.03.035

Lai, M., 1992a, 'Genetic recombination in RNA viruses', Genetic diversity of RNA viruses, pp. 21-32, Springer, Berlin, Heidelberg.

Lai, M., 1992b, 'RNA recombination in animal and plant viruses', Microbiological Reviews 56(1), 61-79. https://doi.org/10.1128/MMBR.56.1.61-79.1992

Lai, M., Baric, R., Makino, S., Keck, J., Egbert, J., Leibowitz, J. et al., 1985, 'Recombination between nonsegmented RNA genomes of murine coronaviruses', Journal of Virology 56(2), 449-456. https://doi.org/10.1128/JVI.56.2.449-456.1985

Lau, S.K., Woo, P.C., Yip, C.C., Fan, R.Y., Huang, Y., Wang, M. et al., 2012, 'Isolation and characterization of a novel Betacoronavirus subgroup A coronavirus, rabbit coronavirus HKU14, from domestic rabbits', Journal of Virology 86(10) 5481-5496. https://doi.org/10.1128/JVI.06927-11

Lee, S.S. \& Wong, N.S., 2015, 'Probable transmission chains of Middle East respiratory syndrome coronavirus and the multiple generations of secondary infection in
South Korea', International Journal of Infectious Diseases 38, 65-67. https://doi. org/10.1016/j.ijid.2015.07.014

Li, Q., Guan, X., Wu, P., Wang, X., Zhou, L., Tong, Y. et al., 2020, 'Early transmission dynamics in Wuhan, China, of novel coronavirus-infected pneumonia', New England Journal of Medicine 382, 1199-1207. https://doi.org/10.1056/ NEJMoa2001316.

Li, W., Shi, Z., Yu, M., Ren, W., Smith, C., Epstein, J.H. et al., 2005, 'Bats are natura reservoirs of SARS-like coronaviruses', Science 310(5748), 676-679. https://doi. org/10.1126/science.1118391

Li, X., Zai, J., Zhao, Q., Nie, Q., Li, Y., Foley, B.T. et al., 2020, 'Evolutionary history, potential intermediate animal host, and cross-species analyses of SARS-CoV-2', Journal of Medical Virology 92(6), 602-611. https://doi.org/10.1002/jmv.25731

Liang, G., Chen, Q., Xu, J., Liu, Y., Lim, W., Peiris, J. et al., 2004, 'Laboratory diagnosis of four recent sporadic cases of community-acquired SARS, Guangdong Province, China', Emerging Infectious Diseases 10(10), 1774. https://doi.org/10.3201/ eid1010.040445

Lim, P.L., Kurup, A., Gopalakrishna, G., Chan, K.P., Wong, C.W., Ng, L.C. et al., 2004, 'Laboratory-acquired severe acute respiratory syndrome', New England Journal of

Lim, S.-I., Choi, S., Lim, J.-A., Jeoung, H.-Y., Song, J.-Y., Dela Pena, R. et al., 2013, 'Complete genome analysis of canine respiratory coronavirus', Genome Announcements 1(1), e00093-00012. https://doi.org/10.1128/genomeA.00093-12

Lim, Y.X., Ng, Y.L., Tam, J.P. \& Liu, D.X., 2016, 'Human coronaviruses: A review of virushost interactions', Diseases 4(3), 26. https://doi.org/10.3390/diseases4030026

Liu, Z., Xiao, X., Wei, X., Li, J., Yang, J., Tan, H. et al., 2020, 'Composition and divergence of coronavirus spike proteins and host ACE2 receptors predict potential intermediate hosts of SARS-CoV-2', Journal of Medical Virology 92(6), 595-601. https://doi.org/10.1002/jmv.25726

Lu, G., Hu, Y., Wang, Q., Qi, J., Gao, F., Li, Y. et al., 2013, 'Molecular basis of binding between novel human coronavirus MERS-CoV and its receptor CD26', Nature 500(7461), 227-231. https://doi.org/10.1038/nature12328

Lu, L., Liu, Q., Du, L. \& Jiang, S., 2013, 'Middle East respiratory syndrome coronavirus (MERS-CoV): Challenges in identifying its source and controlling its spread', Microbes and Infection 15(8-9), 625-629. https://doi.org/10.1016/j.micinf.2013.06.003

Lu, R., Zhao, X., Li, J., Niu, P., Yang, B., Wu, H. et al., 2020, 'Genomic characterisation and epidemiology of 2019 novel coronavirus: Implications for virus origins and receptor binding', The Lancet 395(10224), 565-574. https://doi.org/10.1016/ S0140-6736(20)30251-8

Mackenzie, J.S. \& Smith, D.W., 2020, COVID-19: 'A novel zoonotic disease caused by a coronavirus from China: What we know and what we don't', Microbiology Australia 41(1), 45-50.

Majhdi, F., Minocha, H. \& Kapil, S., 1997, 'Isolation and characterization of a coronavirus from elk calves with diarrhea', Journal of Clinical Microbiology 35(11) 2937-2942. https://doi.org/10.1128/JCM.35.11.2937-2942.1997

Masters, P.S. \& Perlman, S., 2013, 'Coronaviridae', in D.M. Knipe, \& P.M. Howley (eds.), Fields virology, 6th edn., pp. 825-858, Lippincot Williams \& Wilkins, Philadelphia.

McIntosh, K., Dees, J.H., Becker, W.B., Kapikian, A.Z. \& Chanock, R.M., 1967, 'Recovery in tracheal organ cultures of novel viruses from patients with respiratory disease', in tracheal organ cultures of novel viruses from patients with respiratory disease,
Proceedings of the National Academy of Sciences 57(4), 933-940. https://doi. Proceedings of the National
org/10.1073/pnas.57.4.933

Müller, A., Tillmann, R., Simon, A. \& Schildgen, O., 2008, 'Stability of human metapneumovirus and human coronavirus NL63 on medical instruments and in the patient environment', Journal of Hospital Infection 69(4), 406-408. https:// the patient environment', Journal of
doi.org/10.1016/j.jhin.2008.04.017

Navas-Martin, S. \& Weiss, S.R., 2003, 'SARS: Lessons learned from other coronaviruses', Viral Immunology 16(4), 461-474. https://doi.org/10.1089/088282403771926292

Peiris, J., Lai, S., Poon, L., Guan, Y., Yam, L., Lim, W. et al., 2003, 'Coronavirus as a possible cause of severe acute respiratory syndrome', The Lancet 361(9366), 1319-1325. https://doi.org/10.1016/S0140-6736(03)13077-2

Peiris, J.S., Yuen, K.Y., Osterhaus, A.D. \& Stöhr, K., 2003, 'The severe acute respiratory syndrome', New England Journal of Medicine 349(25), 2431-2441. https://doi. org/10.1056/NEJMra032498

Perlman, S. \& Netland, J., 2009, 'Coronaviruses post-SARS: Update on replication and pathogenesis', Nature Reviews Microbiology 7(6), 439-450. https://doi. org/10.1038/nrmicro2147 
Pfefferle, S., Oppong, S., Drexler, J.F., Gloza-Rausch, F., Ipsen, A., Seebens, A. et al., 2009, 'Distant relatives of severe acute respiratory syndrome coronavirus and close relatives of human coronavirus $229 \mathrm{E}$ in bats, Ghana', Emerging Infectious Diseases 15(9), 1377. https://doi.org/10.3201/eid1509.090224

Raj, V.S., Farag, E.A., Reusken, C.B., Lamers, M.M., Pas, S.D., Voermans, J. et al., 2014, 'Isolation of MERS coronavirus from a dromedary camel, Qatar, 2014', Emerging Infectious Diseases 20(8), 1339. https://doi.org/10.3201/eid2008.140663

Reusken, C.B., Haagmans, B.L., Müller, M.A., Gutierrez, C., Godeke, G.-J., Meyer, B. et al., 2013, 'Middle East respiratory syndrome coronavirus neutralising serum antibodies in dromedary camels: A comparative serological study', The Lancet Infectious Diseases 13(10), 859-866. https://doi.org/10.1016/S1473-3099(13)70164-6

Reusken, C.B., Raj, V.S., Koopmans, M.P. \& Haagmans, B.L., 2016, 'Cross host transmission in the emergence of MERS coronavirus', Current Opinion in Virology transmission in the emergence of MERS coronavirus', Curren
$16,55-62$. https://doi.org/10.1016/j.coviro.2016.01.004

Richard, M., Knauf, S., Lawrence, P., Mather, A.E., Munster, V.J., Müller, M.A. et al., 2017 , 'Factors determining human-to-human transmissibility of zoonotic
pathogens via contact', Current Opinion in Virology 22, 7-12. https://doi. org/10.1016/j.coviro.2016.11.004

Sabir, J.S., Lam, T.T.-Y., Ahmed, M.M., Li, L., Shen, Y., Abo-Aba, S.E. et al., 2016, 'Cocirculation of three camel coronavirus species and recombination of MERS-CoVs in Saudi Arabia', Science 351(6268), 81-84. https://doi.org/10.1126/science. aac8608

Saif, L., 2004, 'Animal coronavirus vaccines: Lessons for SARS', Developments in Biologicals 119, 129-140. PMID: 15742624.

Simon-Loriere, E. \& Holmes, E.C., 2011, 'Why do RNA viruses recombine?' Nature Reviews Microbiology 9(8), 617-626. https://doi.org/10.1038/nrmicro2614

Sipulwa, L.A., Ongus, J.R., Coldren, R.L. \& Bulimo, W.D., 2016, 'Molecular characterization of human coronaviruses and their circulation dynamics in Kenya, 2009-2012', Virology Journal 13(1), 18. https://doi.org/10.1186/s12985-016$0474-x$

Steinhauer, D.A., Domingo, E. \& Holland, J.J., 1992, 'Lack of evidence for proofreading mechanisms associated with an RNA virus polymerase', Gene 122(2), 281-288. https://doi.org/10.1016/0378-1119(92)90216-C

Summers, J., Cheng, H.Y., Lin, H.H., Barnard, L.T., Kvalsvig, A., Wilson, N. et al., 2020 'Potential lessons from the taiwan and new zealand health responses to the COVID-19 pandemic', The Lancet Regional Health-Western Pacific, 100044

Tao, Y., Shi, M., Chommanard, C., Queen, K., Zhang, J., Markotter, W. et al., 2017 'Surveillance of bat coronaviruses in Kenya identifies relatives of human coronaviruses NL63 and 229E and their recombination history', Journal of Virology 91(5), e01953-e01916. https://doi.org/10.1128/JVI.01953-16

Tong, S., Conrardy, C., Ruone, S., Kuzmin, I.V., Guo, X., Tao, Y. et al., 2009, 'Detection of novel SARS-like and other coronaviruses in bats from Kenya', Emerging Infectious Diseases 15(3), 482. https://doi.org/10.3201/eid1503.081013

Tsang, K. \& Zhong, N.S., 2003, 'SARS: Pharmacotherapy', Respirology 8(s1), S25-S30. https://doi.org/10.1046/j.1440-1843.2003.00525.x

Tsunemitsu, H., El-Kanawati, Z.R., Smith, D.R., Reed, H.H. \& Saif, L.J., 1995, 'Isolation of coronaviruses antigenically indistinguishable from bovine coronavirus from wild ruminants with diarrhea', Journal of Clinical Microbiology 33(12), 3264-3269. https://doi.org/10.1128/JCM.33.12.3264-3269.1995

Tyrrell, D. \& Bynoe, M., 1966, 'Cultivation of viruses from a high proportion of patients with colds', The Lancet 287(7428), 76-77. https://doi.org/10.1016/S01406736(66) $92364-6$

Van der Hoek, L., 2007, 'Human coronaviruses: What do they cause?' Antiviral Therapy 12 (4 Pt B), 651.

Van der Hoek, L., Pyrc, K., Jebbink, M.F., Vermeulen-Oost, W., Berkhout, R.J., Wolthers, K.C. et al., 2004, 'Identification of a new human coronavirus', Nature Medicine 10(4), 368. https://doi.org/10.1038/nm1024

Van Doremalen, N., Bushmaker, T., Morris, D.H., Holbrook, M.G., Gamble, A., Williamson, B.N. et al., 2020, 'Aerosol and surface stability of SARS-CoV-2 as compared 'with SARS-CoV-1', New England Journal of Medicine 382(16), 1564-1567. https://doi.org/10.1056/NEJMc2004973

Van Doremalen, N., Bushmaker, T. \& Munster, V., 2013, 'Stability of Middle East respiratory syndrome coronavirus (MERS-CoV) under different environmental conditions', Eurosurveillance 18(38), 20590. https://doi.org/10.2807/1560-7917. ES2013.18.38.20590
Wang, B., Potter, S.J., Lin, Y., Cunningham, A.L., Dwyer, D.E., Su, Y. et al., 2005, 'Rapid and sensitive detection of severe acute respiratory syndrome coronavirus by rolling circle amplification', Journal of Clinical Microbiology 43(5), 2339-2344. rolling circle amplification', Journal of Clinical Micr
https://doi.org/10.1128/JCM.43.5.2339-2344.2005

Wang, D., Hu, B., Hu, C., Zhu, F., Liu, X., Zhang, J. et al., 2020, 'Clinical characteristics of 138 hospitalized patients with 2019 novel coronavirus-infected pneumonia in Wuhan, China', JAMA 323(11), 1061-1069. https://doi.org/10.1001/ jama.2020.1585

Wang, L.-F., Shi, Z., Zhang, S., Field, H., Daszak, P. \& Eaton, B.T., 2006, 'Review of bats and SARS', Emerging Infectious Diseases 12(12), 1834. https://doi.org/10.3201/ eid1212.060401

Wang, W., Lin, X.-D., Guo, W.-P., Zhou, R.-H., Wang, M.-R., Wang, C.-Q. et al., 2015, 'Discovery, diversity and evolution of novel coronaviruses sampled from rodents in China', Virology 474, 19-27. https://doi.org/10.1016/j.virol.2014.10.017

Wang, X.-W., Li, J.-S., Guo, T.-K., Zhen, B., Kong, Q.-X., Yi, B. et al., 2005, 'Concentration and detection of SARS coronavirus in sewage from Xiao Tang Shan Hospital and the 309th Hospital', Journal of Virological Methods 128(1-2), 156-161. https:// doi.org/10.1016/j.jviromet.2005.08.010

Wege, H. \& Ter Meulen, V., 1982, 'The structure and replication of coronaviruses', in Current topics in microbiology and immunology, pp. 131-163, Springer, Berlin, Heidelberg.

Weiss, S.R. \& Navas-Martin, S., 2005, 'Coronavirus pathogenesis and the emerging pathogen severe acute respiratory syndrome coronavirus', Microbiology and Molecular Biology Reviews 69(4), 635-664. https://doi.org/10.1128/ MMBR.69.4.635-664.2005

Widagdo, W., Okba, N.M., Raj, V.S. \& Haagmans, B.L., 2017, 'MERS-coronavirus: From discovery to intervention', One Health 3, 11-16. https://doi.org/10.1016/j onehlt.2016.12.001

Woo, P.C., Lau, S.K., Chu, C.-M., Chan, K.-H., Tsoi, H.-W., Huang, Y. et al., 2005 'Characterization and complete genome sequence of a novel coronavirus, coronavirus HKU1, from patients with pneumonia', Journal of Virology 79(2), 884-895. https://doi.org/10.1128/JVI.79.2.884-895.2005

Woo, P.C., Lau, S.K., Lam, C.S., Lau, C.C., Tsang, A.K., Lau, J.H. et al., 2012, 'Discovery of seven novel mammalian and avian coronaviruses in Deltacoronavirus supports bat coronaviruses as the gene source of Alphacoronavirus and Betacoronavirus and avian coronaviruses as the gene source of Gammacoronavirus and Deltacoronavirus', Journal of Virology 86(7), 3995-4008. https://doi.org/10.1128/ JVI.06540-11

Woo, P.C., Lau, S.K., Wernery, U., Wong, E.Y., Tsang, A.K., Johnson, B. et al., 2014 'Novel betacoronavirus in dromedaries of the Middle East, 2013', Emerging Infectious Diseases 20(4), 560. https://doi.org/10.3201/eid2004.131769

Young, B.E., Ong, S.W.X., Kalimuddin, S., Low, J.G., Tan, S.Y., Loh, J. et al., 2020, 'Epidemiologic features and clinical course of patients infected with SARS-CoV-2 in Singapore', JAMA 323(15), 1488-1494. https://doi.org/10.1001/jama.2020.3204

Zaki, A.M., Van Boheemen, S., Bestebroer, T.M., Osterhaus, A.D. \& Fouchier, R.A 2012, 'Isolation of a novel coronavirus from a man with pneumonia in Saud Arabia', New England Journal of Medicine 367(19), 1814-1820. https://doi. org/10.1056/NEJMoa1211721

Zhang, S.-f., Tuo, J.-I., Huang, X.-b., Zhu, X., Zhang, D.-m., Zhou, K. et al., 2018 'Epidemiology characteristics of human coronaviruses in patients with respiratory infection symptoms and phylogenetic analysis of HCoV-OC43 during 2010-2015 in Guangzhou', PLoS One 13(1), e0191789. https://doi.org/10.1371/journal. pone.0191789

Zhang, W., Du, R.-H., Li, B., Zheng, X.-S., Yang, X.-L., Hu, B. et al., 2020, 'Molecular and serological investigation of 2019-nCoV infected patients: Implication of multiple shedding routes', Emerging Microbes \& Infections 9(1), 386-389. https://doi.org/ 10.1080/22221751.2020.1729071

Zhu, N., Zhang, D., Wang, W., Li, X., Yang, B., Song, J. et al., 2020, 'A novel coronavirus from patients with pneumonia in China, 2019', New England Journal of Medicine 382, 772-733. https://doi.org/10.1056/NEJMoa2001017

Zou, X., Chen, K., Zou, J., Han, P., Hao, J. \& Han, Z., 2020, 'Single-cell RNA-seq data analysis on the receptor ACE2 expression reveals the potential risk of different human organs vulnerable to $2019-\mathrm{nCoV}$ infection', Frontiers of Medicine 14, 1-8. https://doi.org/10.1007/s11684-020-0754-0 